\title{
An Australian study of possible selves perceived by undergraduate
}

\section{engineering students}

Bennett, D., \& Male, S. A. (2016). An Australian study of possible selves perceived by undergraduate engineering students. European Journal of Engineering Education, 1-15. doi: 10.1080/03043797.2016.1208149

Authors:

Professor Dawn Bennett (corresponding author)

Research and Graduate Studies

Curtin University

404/building 209

GPO Box U1987

Perth, Western Australia

WA 6845

Tel +61 892664482

Fax +61 892663818

Email: dawn.bennett@curtin.edu.au

Professor Dawn Bennett is Distinguished Research Fellow and Director of the Creative Workforce initiative at Curtin University. Recent research has focused on identity development, creative labour markets and research frameworks, with a particular focus on the development and impact of identity development during higher education.

Assistant Professor Sally Male

School of Electrical, Electronic and Computer Engineering

M018, 35 Stirling Highway, Crawley

Western Australia 6009

University of Western Australia

Email sally.male@uwa.edu.au

Sally Male undertakes research in engineering education and women in engineering. Her interests are in gender inclusivity, curriculum design, competencies, industry engagement, and threshold concepts. She is qualified in electrical engineering and completed her $\mathrm{PhD}$ in engineering education, and is a Fellow of Engineers Australia. 


\section{An Australian study of possible selves perceived by undergraduate engineering students}

In this study we worked with second year engineering students at an Australian university to examine previously identified threshold concepts within the theoretical framework of Possible Selves. Using a workshop approach, students were encouraged to consider their future lives and work, including their engineering fears, expectations and aspirations. The findings revealed many students to have a poor understanding of the realities of engineering work. Moreover, perceived gaps between self-efficacy and the requirements of engineering work appeared to be motivating if students deemed it possible to reduce the gap, but demotivating if they identified a characteristic over which there was perceived to be no control. The study suggests that these engineering students needed more opportunities to explore both the roles of engineers and their own possible selves. Overall the findings indicate that higher education students may need encouragement and support to explore potential future roles, and they strengthen calls for further research in this area.

Keywords higher education; possible selves; identity; engineering education

Acknowledgement This paper builds on David Parkinson's final-year research project, for which he is thanked. Caroline Baillie and Sally Male supervised David's project. We are grateful to the students who participated in the workshops, to coordinator Dianne Hesterman, and to the unit's workshop facilitators. We also thank Jane Coffey and Rebecca Coleman, who assisted with the coding and initial analysis of student data. Part-support for this project was provided by the Australian Government's Office for Learning and Teaching. The views expressed in this paper do not necessarily reflect the views of the Australian Government Office for Learning and Teaching. The workshop tools are available in full and without charge at www.thetileapproach.ning.com. 


\section{Introduction}

Despite the global financial crisis, Australia experienced a resources boom that led to a welldocumented skills shortage in engineering (Australian National Engineering Taskforce 2010; Kaspura 2012; The Senate 2012; Yates 2012). The skills shortage has also been felt elsewhere; in the UK, which has suffered from economic downturn in recent years, a shortage of engineers was acknowledged as a risk to balanced economic recovery (Harrison 2012).

The recruitment and retention of engineering graduates has been a key challenge for the supply of engineers in Australia, with research by Tilli and Trevelyan (2010) reporting that approximately $40 \%$ of engineering graduates do not go on to work in engineering-related roles. Alongside this is the problematic issue of attracting and retaining engineering students. Engineering undergraduate courses in Australia and elsewhere have high rates of student attrition, with attrition from Australian bachelor-level engineering programs standing at around 35\% (Godfrey and King 2011). The high attrition is seen as not only "an excessive loss to the qualified workforce, but a loss of return on public investment” (Godfrey, Aubrey and King 2010,1). The attrition of students and graduate engineers has led to concerns that students may enter engineering study without a sense of motivation and commitment, and without understanding the realities of either their degree program or engineering work.

The study reported here sought to further understand these issues by exploring the thinking of undergraduate engineering students in relation to their future careers. To do this we extended previous research that had employed threshold concept theory in the discipline of engineering (Male 2012; Male and Baillie 2011; Parkinson 2011). The earlier research revealed three concepts that are critical to student achievement: namely, students' understanding of the 'roles of engineers'; students' perception of the 'value of learning' new material; and the need for 'self-directed learning', both as students and into professional life. These concepts had been found to be troublesome for many students and also likely to be linked, such that greater understanding of the roles of engineers and the value of learning was seen to assist self-directed learning. We theorised that insights into students' self-efficacy and the development of identity might provide further explanation.

Identity salience can be thought of as 'the probability that an identity will be invoked across a variety of situations, or alternatively across persons in a given situation' (Stryker and Burke 2000, 286). Given that identity is socially constructed, "its content and the behaviors associated with it are likely to be shaped by what makes sense in the moment” (Oyserman and Destin 2010, 1005). The study drew attention to the need for students to develop salient 
identities as a core component of their professional learning, and it raised the possibility of employing a future-oriented approach to achieve this.

We note that this is an Australian study. Whilst it will contribute to a global picture, the findings are likely to contrast with those from concurrent studies in Europe. This is because engineering students in many Australian universities have little exposure to engineering practice in the early years of engineering study. Also, many Australian engineering educators lack experience that would help expose students to practice before their formal workplace learning experiences. This was acknowledged by Cameron, Reidsema and Hadgraft (2011, 109), whose survey of 600 Australian engineering academics revealed the 'relative lack of engineering academics with professional experience beyond four years' and the lack of currency of professional experience, "which in most cases was gained many years prior to entry into the higher education sector" (109). Although we expect that the importance of exploring possible future selves and self-efficacy crosses international boundaries, the above factors indicate that students' awareness and self-efficacy could differ across contexts.

\section{Theoretical framework and rationale}

\subsection{Possible selves: our central theoretical framework for this study}

Described as “an evaluative and interpretive context for the current view of self” (Marcus and Nurius 1986, 962), possible selves are people’s projections about what they hope to become, what they expect to become, and what they fear becoming. The possible selves framework is closely related to Marcia's (1966) identity status framework, which relates the formation of identity to levels of crisis and commitment. In practical terms the framework describes how individuals plan towards realising their future personas and achieving their career aspirations (Schnare, MacIntyre and Doucette 2012).

Where much identity research is focused on antecedents to present identity, 'possible selves' concerns the planning and implementation of strategies towards the realisation or avoidance of possible future identities. This aligns with Sfard and Prusak's $(2005,18)$ notion of actual and designated identities, the latter having “the potential to become a part of one's actual identity”. The transition between actual and designated identities can be prompted by multiple factors including labels of giftedness, significant others, changes of circumstance, and education-related decisions such as those made prior to and during higher education. We hoped that the future orientation of possible selves would help explain the significance of the 
previously identified threshold concepts and might encourage students to take an active role in developing future selves and considering these in relation to their learning.

\subsection{Threshold concept theory: the theory within which our previous research was framed}

The negotiation of actual or potential possible selves is often a threshold experience, and we built on the earlier threshold concept research to enhance understanding of engineering students' thinking about self and career. In threshold concept theory, Meyer and Land (2003) propose that many disciplines have distinct concepts which are critical to students' achievement as learners and as future workers. These concepts can be crucial gateways to students' progress, and for many students they are troublesome and challenging (Harlow, Scott, Peter and Cowie 2011). Acknowledging that the features of threshold concepts continue to be debated, Quinlan et al. $(2013,586)$ describe 'non-negotiable features': namely that “all threshold concepts are epistemologically transformative and ontologically transformative ... once a student has grasped the concepts they will 'see' the world differently-their way of knowing (epistemology) and related ways of being in the world (ontologically) will change”. The earlier research revealed that this change will prove troublesome for some students and not for others, and we employed the possible selves framework to help explain this.

\subsection{Identity-based motivation}

Adolescents are more likely to engage in learning when it is perceived as relevant to their future; however, Bennett (2012, 28) has suggested that higher education students are rarely encouraged to make these crucial links. As a result, "few students are accustomed to such open-ended, boundaryless thinking”. Similarly, Csikszentmihalyi (2007, xix) has advocated the need for educators "to help students find out what they truly love, and help them to immerse themselves in the domain - be it poetry or physics, engineering or dance”.

The theories of threshold concepts and possible selves provided a framework to investigate whether and how students might find understanding the roles of engineers to be transformative and troublesome, but we also needed to consider whether this might be linked to their perception of the value and relevance of their learning to their future lives and work. Mindful of the role of motivation in identity formation and future-oriented thinking, we addressed this by incorporating aspects of Oyserman's work (2007) on identity-based motivation (IBM). This model acknowledges that people favour ideas that make sense "in the moment” and that "identities are dynamically constructed in context” (1001). 
Of particular relevance here is the motivation aspect of Oyserman's work, which has shown that people "prefer identity-congruent to identity-incongruent actions. When action feels identity congruent, experienced difficulty highlights that the behavior is important and meaningful. When action feels identity incongruent, the same difficulty suggests that the behavior is pointless and 'not for people like me'” (Oyserman and Destin 2010, 1001). With the three frameworks in mind, we devised a workshop that exposed perceived gaps between self and engineering professional; sources of information and knowledge about engineering work; and feared, expected and desired conceptions of self and career.

\section{Methodology}

This study explored the presage thinking of undergraduate engineering students in relation to their future careers. In line with Biggs (1989), presage in this context refers to what students have brought to their engineering studies. This includes students' prior experience and knowledge of engineering and is influenced by elements such as their personal beliefs and values, age, and cultural background. The research sought to answer three key questions:

1. What do students want to achieve as engineers?

2. What are students' perceptions of engineering practice?

3. After considering their perceptions of engineering practice, what fears do students hold about their ability to achieve their career aspirations?

The study hoped to highlight strategies through which educators could encourage students' development of presage thinking in relation to their engineering futures, thereby informing the necessary development of their salient or discursive identities (Allie et al. 2009). We involved students in a variety of activities in which they thought creatively about possible engineering roles and their future lives and careers. We challenged them to think both subjectively (how they might see themselves as engineers and as individuals) and objectively (how others might see them in the future).

\subsection{Approach}

The study was situated at a large urban Australian university. Forty-nine undergraduate engineering students participated in a two-hour workshop conducted at the start of a foundation course (unit) on motion. The study was explained to students and their confidentiality was assured. Students completed a number of activities and reflections, which are presented along with the findings below. Students were invited to submit copies of their written responses for analysis by the research team, and 38 students returned responses to one 
or more of the data collection instruments. The length of student responses ranged from shortresponse answers to paragraphs of text, depending on question and activity. Although the sample was relatively small (38 students), the students contributed multiple forms of data including individual reflections, discussion observations and group responses.

Participating students were in their second or third year of undergraduate engineering study and had a mean age of 18.4 years, which indicates that most had commenced university the year following high school completion. We note this because we would anticipate a different result from a cohort that included mature learners. Two participants did not identify their age. Five participants were female. The students' disciplinary groups included chemical/petroleum, civil, electrical/electronic (hereafter referred to as electrical), environmental, mechanical/mechatronic (hereafter referred to as mechanical), and mining. In this paper we group student responses according to their proposed engineering discipline: for example, 'mechanical students' are students considering specialist study in mechanical or mechatronic engineering. Response rates for each activity are noted below with the findings.

This was a transcendental phenomenological study (Creswell 2007) involving analytical procedures as described by Moustakas (1994). This approach emphasises belief in the data as reported by participants and begins with identifying key statements and clustering them into themes and meaningful units. Researchers not otherwise involved with the study coded the responses to remove identifiable data, after which the lead researchers independently coded the data. Coding was compared before final refinements were made to the codebook. NVivo qualitative analysis software was used for the coding and analysis of emergent themes.

\subsection{Materials}

Each workshop incorporated whole-class discussion, individual reflection, brainstorming, and group work in and outside discipline groups. The workshop was developed specifically for the engineering context and extended Parkinson's (2011) work on threshold concepts by incorporating the revised threshold concepts described earlier. To establish their motivations we also asked students to consider their aspirations and goals, and in so doing we challenged students to adopt future-oriented thinking in which they imagined what they hoped to become, what they expected to become, and what they feared becoming. Finally, students were asked to identify perceived differences between themselves and an engineer. This enabled us to see whether these differences were identity-congruent or identity-incongruent features. 
At the start of the workshop, students noted the 'one thing they wanted to achieve' as an engineer. Students were invited to share career goals with their peers, which many students did. This prompted discussion and the sharing of engineering goals and aspirations. Students then joined peers in the same engineering discipline. Students began the second activity by completing an individual self-reflection. Later, having discussed their responses with other students, they created a group summary of engineering characteristics to share with the class. We include each question in full in the following section.

\section{Findings and analysis}

\subsection{Activity 1: Career aspirations and desirable selves}

After an icebreaker activity, students were challenged to write down what they wanted to achieve as an engineer. This required a short-answer response in which students had to distil their thinking down to a single statement. Thirty-two students (65.3\%) submitted their responses, and common themes concerned the desire for enjoyable work, making a difference to the lives of others, environmental concerns, and a desire to be well known. Eight students focused on intrinsic satisfaction with comments such having a 'passion for creating and problem solving.'

Nine students linked their engineering goals to improving the lives of others or the environment, specifying broad goals such as:

"Innovation/breakthrough in a particular chemical process that improves life/lives."

"I want to make a difference to the lives of people who are suffering."

"Build something that improves the average person’s quality of life, enjoyment of life.”

We note that the engineering degree in which the students were enrolled included a course on engineering challenges within a global context. This may have heightened students' awareness of engineers' responsibilities and their potential value to society and the environment. Indeed, social justice emerged strongly throughout the students' responses:

\footnotetext{
"If water, help a village develop a waste management system... something that helps the wellbeing of people.” (civil)

“To develop/enhance current technology that better humanity as a whole.” (mechanical)
} 
A number of students volunteered to share their goals with peers, and this prompted further examples and discussion. Some students were able to explain what had influenced their goals, and two students described previous employment; however, the task of imagining career and career goals was new for a large majority of students. Given the pressing need to select an engineering discipline as their major study during the following weeks, this was troubling for both students and faculty.

\subsection{Activity 2: Career preview and possible selves}

Career preview relates to advance information about the characteristics of a career. It can also be referred to as a purview, or overview. The second workshop activity was titled 'roles of engineers' after one of the new threshold concepts that emerged from Parkinson's (2011) earlier research. We added the dimension of possible selves by incorporating future-oriented questions. The activity was completed as an individual reflection that challenged students to consider a number of questions and issues around their individual perceptions of self and career. We hoped that the question about perceived difference would reveal something about identity congruence and incongruence.

Students were seated in discipline groups, but they did not communicate with peers until they had completed the self-reflection. The questions, which are discussed in turn in the following section, were as follows:

1. What does a engineer look like? (Student inserted engineering discipline.)

2. What differences are there (if any) between the above characteristics and you as a person?

3. What do you see as the role of an engineer?

4. What will your personal role be?

5. How will the learning in this course contribute to your development as an engineer?

6. Imagine yourself in 15 years' time.

a. What will you be doing?

b. In a sentence, describe what you dream you will have achieved as an engineer over this time.

\subsection{Self reflection questions}

\subsubsection{Question 1: What does an engineer look like?}

Students were asked to consider their preferred engineering discipline and respond to the question: 'What does a engineer look like?' Thirty-seven students (75.5\%) submitted their self-reflections for analysis. They used multiple terms to describe an engineer, 
the most common being that engineers are creative $(n=16)$ and knowledgeable $(n=12)$. Engineers were also seen as intelligent $(n=6)$, good leaders $(n=5)$, independent $(n=5)$, team players $(n=5)$ and innovative $(n=5)$.

Differences in the characteristics described for each engineering discipline were evident from students' responses: for example, no chemical engineering students identified creativity as a characteristic of engineers, yet over half of them noted knowledge. Conversely, knowledge did not feature strongly among any of the other disciplines. All six students who mentioned intelligence were from mechanical engineering. We do not attempt to generalise from this small sample, but it is a line of inquiry that deserves attention in future research.

\subsubsection{Question 2: Differences between self and engineering}

With a view to understanding students' self-efficacy, the next question asked: 'What differences are there (if any) between the above characteristics and you as a person?' Thirtythree students submitted their responses and they identified multiple differences relating to design, engineering knowledge, and teamwork or the ability to work with others. Chief amongst the differences was creativity. Further analysis found this concern to come almost exclusively from mechanical engineering students, of whom $65 \%$ were concerned about being uncreative or lacking innovation. We later discovered that students had watched a video on engineering practice during an orientation session for the same course, held the previous week, and that the video had emphasised the need for creative thinking. This highlighted that as educators we are often unaware of the concepts that are troubling for students, and that it is difficult to predict where scaffolding might be required.

\subsubsection{Question 3: Career preview: Roles of an engineer}

Following Parkinson (2011), students next considered the question: 'What do you see as the role of an engineer?' The responses to this question were again coded by engineering discipline. Not surprisingly, most of the responses linked to technical requirements and specialisations: for example, mechanical engineering students $(n=13)$ wrote of the technical focus in their future roles: "To use knowledge of fluids, mechanics and thermodynamics to design systems and solve problems”.

Design featured in 12 of the 13 responses, and three students mentioned project management and working as part of a team. The seven chemical engineering students mentioned design $(n=2)$, technical processing $(n=4)$ and testing $(n=1)$, and all five civil 
engineering students wrote of design and construction. There were distinct differences between disciplines in the terms used to describe the characteristics of an engineer. It is possible that students oriented towards the more discrete and technically complex disciplines identify more with the need for knowledge. Indeed, students often identified the specific type of knowledge required: for example, "good knowledge of electronics” (electrical); and "knowledgeable in chemical engineering” (chemical).

Informed selection of an engineering discipline is an aspect of career choice that deserves further attention. This study was undertaken in a state with a strong mining industry and a growing oil and gas industry, and yet students' descriptions of engineering practice were limited and in some ways inconsistent with employment in these local industries. Graduates are likely to find employment in operations and maintenance engineering; yet design and construction dominated students' narratives. When identifying the roles of engineers in their chosen disciplines, the roles closest to operations and maintenance came from one mechatronic student who mentioned maintaining equipment, and one mechanical student who wrote: “monitor/improve current mechanical operations”.

The lack of awareness of engineering roles in the resources industries could also explain low interest in some disciplines. Within the study cohort only two students nominated electrical engineering as their most likely specialist discipline, and they described the role of an electrical engineer as:

\footnotetext{
"Building foundations of an electricity powered society."

“To engineer electrical stuff??”
}

Within the study region there is much local employment for engineers in control and instrumentation. Process plants and mechanical operations abound with automated controls. Electrical engineers plan decision algorithms, write specifications, manage construction, commissioning and operations, and improve and decommission data acquisition and control systems. These systems are critical to safety and efficiency. Further research could explicitly explore students' awareness of local or regional opportunities such as these, which were not mentioned by the cohort.

\subsubsection{Question 4: Imagining a personal role}

Asked what their personal role as an engineer might be, responses revealed the four overarching themes illustrated at Figure 1. Two students were unable to imagine a personal 
role, with one student writing: 'No idea', and another writing: 'How can anyone answer this question??' Three students failed to answer. The other 32 responses suggest that many desired personal roles are not directly aligned with students' intended engineering discipline. As an example, none of the three students who envisaged an environmental role were studying environmental engineering. Students included both intrinsic and extrinsic factors in their responses, with extrinsic aspirations referring to things such as money and recognition, and intrinsic aspirations relating to personally important things such as relationships and career satisfaction. Students focused on work-life balance, enjoyable work and mental stimulation.

[Figure 1: Student responses: Personal role as an engineer (\% of coded responses)]

This finding gives us an insight into the broader motivational drivers of the students, some of whom make explicit links between their broader passions (an interest in social justice for example) and engineering. For others the connection is unclear and perhaps unexplored, suggesting a diffuse (unexplored) identity (Marcia, 1966). This has obvious implications for the problematic issue of student and graduate attrition: as Coffey has argued (2012, 5), intrinsic motivation and commitment to career choice 'have a more significant impact on retention than traditional and often short-term extrinsic rewards, such as the payment of bonuses or wage rises’. Making explicit links between students’ intrinsic motivations and engineering study and practice emerges as a crucial concern for educators.

\subsubsection{Question 5: How will the learning in this course contribute to your development as an engineer?}

The study was undertaken as part of a course (unit of study) titled 'motion', which is one of four core foundation courses with the engineering degree program. Asked what contribution the foundation course might make to their development as engineers, students identified knowledge, teamwork and technical skill development. Teamwork most probably featured highly because students were aware of the team-based, semester-long project that formed a major assessment item. They also mentioned that working on a practical project (in this case, building a rocket) would help them develop associated skills such as problem solving and communication: 'Working in a team and contributing to a project will help in an engineering project with your job’ (mechanical).

Students largely failed to mention the relevance of the course beyond its obvious application within mechanical engineering ('Race cars are all about motion'), and even 
among the mechanical engineers the relevance could be vague or dismissive: 'Possibly through fluid motion, otherwise none' (mechanical); 'Probably how things move' (mechanical). Some responses illustrate the low level of understanding as to why this foundation unit forms such an important component of the engineering degree:

\author{
“I can’t really say until I have hindsight. I imagine group work is always positive in terms of \\ improving my ability to work in a team.” (civil) \\ "Well, I’m yet to find out." (mechanical) \\ “No idea. Don’t know what we'll be doing yet.” (electrical)
}

\title{
4.3.6. Question 6: 'Looking back' on a future career
}

With a focus on possible selves, the final question challenged students to imagine themselves in 15 years' time and write: i) what they would be doing at that time; and ii) what they 'dreamt' of achieving as an engineer. The most common themes related to working on significant projects $(n=15)$, having an impact on others $(n=6)$, high income $(n=6)$, and enjoyable work ( $n=6)$. As with the earlier self-reflection, the responses reflected both intrinsic and extrinsic drivers:

\footnotetext{
"Working for a big company, travelling around the world building/designing structures.” (civil)

"Rolling in cash because I'm the boss of a big mine.” (mining)

“Job somewhere - hopefully one that I'm enjoying.” (mechanical)

"I would love to have been part of a project that changed the lives of others in a really positive way." (mechanical)

"[To] be content with my job.” (mechatronic)
}

Responses to the second part of the question most commonly concerned a high-level leadership role. Again, students included intrinsic and extrinsic factors in their responses. They mentioned work-life balance, enjoyable work and mental stimulation:

\footnotetext{
"Maybe an engineer but I am also studying business so I hope to have completed an MBA and be moving up the corporate ladder."

"To enjoy my profession as well as to be living a good standard of life economically."

"Created my own company that provides a valuable engineering service in society."
} 


\section{Discussion}

\subsection{Imagining the career: engineering higher education and career preview}

The belief in one's potential to realise a goal or an outcome - self-efficacy - is strongly aligned with student engagement and achievement (Bandura 1997). It presents distinct challenges for engineering educators when students need to look beyond what Minsky (1975) describes as stereotypical 'default values': namely, established perceptions of how something looks or behaves. These perceptions should be challenged from the outset, perhaps even before post-secondary study commences; as Godfrey and King $(2011,58)$ have argued, "Improving advising processes and early exposure to the engineering profession, appear to be a necessity, to prevent students entering engineering without a commitment to the course”.

We have already noted that enhancing students' career previews involves challenging established perceptions of engineering. These perceptions or misperceptions are many and varied (Trevelyan 2011; Trevelyan and Tilli 2007), and one of them is gender bias among both students (Du 2006; Faulkner 2007) and faculty (Fox 2008). Programs in renewable and environmental engineering programs attract higher percentages of women than other engineering programs; yet in this study both male and female students indicated that these applications of engineering were inspirational to them. It is likely that traditional engineering programs could be better aligned with the ambitions of such students by applying concepts in the contexts of environmental engineering or renewable energy. Traditional engineering disciplines such as mechanical, electrical and civil engineering all have applications in these aspects of engineering, and students may not understand or even be aware of these applications. This approach is already recommended as a way of improving gender inclusivity in engineering curricula (Mills, Ayre and Gill 2010).

There are also frequent calls for engineering graduates to have capabilities in engineering for sustainability and social justice (Biswas 2012; Engineering Australia 2011; Engineering Council 2010; Kabo and Baillie 2009). The student responses in this study suggest that many engineering students hold motivations that are consistent with sustainability and social justice. Responsibility lies with engineering educators to guide and support students in developing the requisite capabilities for work in these areas alongside awareness of what types of work may be available.

This study was implemented as part of the motion foundation course, and all engineering students must complete it before going on to study their specialist engineering discipline. It is possible that the mechanical engineering students considered the course to be 
more directly relevant to their futures than did the other students, who struggled to define the relevance of the course. One civil engineering student questioned whether the Motion course had any relevance at all, given that buildings 'don't move'.

The obvious implication here is that students may need guidance and examples in order to understand the relevance of learning which, to academics and course coordinators, is a central and unquestioned component of a degree program. Establishing relevance is key to "seeing the relevance of concepts, resituating the concepts [across, for example, different engineering disciplines and contexts], and integrating new knowledge” (Fischer, Boreham and Nyham 2004, 286), and it cannot be assumed. Establishing relevance enables students to make vital connections between self, learning and their intended field of work. The lack of such links among the students in this study highlights the emphasis on engineering science at the cost of socio-technical competencies and the application of knowledge and skills within engineering practice, which are concerns mirrored elsewhere (Faulkner, 2007; Sullivan, Sheppard \& Macatangay 2009).

One of the key questions asked in engineering over the past two decades is whether the focus on the science of engineering hinders the development of the skills required for engineering practice. It is largely agreed that since World War II the focus on engineering science in engineering programs has increased (Johnson 1996; Prados 1998), with the result that engineering has recently been labelled 'socio-technical' in nature (Leydens, 2012). Consistent with similar research in Europe and the US, competency factors identified for engineers graduating in Australia include technical, non-technical, and attitudinal competencies. These include "communication; working in diverse teams; self-management; professionalism; creativity/problem-solving; management/leadership; engineering business; practical engineering; innovation; contextual responsibilities; [and] applying technical theory” (Male, Bush and Chapman 2011, 161).

The criticism of existing programs has been mainly concerned with closing the gaps between engineering graduates' competencies and the competencies required for engineering practice (Bennett 2010). However, in a landmark review of engineering education, Sullivan, Sheppard and Macatangay $(2009,3)$ have raised the issue of identity development through exposure to practice, explaining that undergraduate engineering programs "struggle to transmit a base of technical knowledge even as it grows exponentially, leaving little room for students to develop the skills and professional identity necessary to meeting the responsibilities of engineering in this new century”. 
The first and third of their four principles for redesigning engineering education have particular relevance here. The first is to provide a professional spine, which entails "engaging in increasingly practice-like experiences ... [as] a central feature of engineering education” (3). The third principle is to integrate identity, knowledge, and skills through approximation to practice. Put simply, 'students need to see what expert practice looks like” (Sullivan, Sheppard \& Macatangay 2009, 3). This study helps explain the necessity for these principles by highlighting the need for students to understand and develop possible selves during a program that emphasises engineering science without sufficient opportunity for students to develop awareness of engineering practice.

\subsection{Imagining self: self preview}

As noted earlier, the study aimed to highlight strategies with which educators could encourage students' development of presage thinking in relation to their future careers in engineering. It did this by adopting the theoretical lens of possible selves and incorporating aspects of identity-based motivation and threshold concept theory. Thinking about future professional roles is necessary for students in any discipline, so why might it be transformative for some students and troublesome for others? The explanation suggested by the theory and borne out in this study is that understanding the roles of engineers may be transformative if the roles are appealing and therefore motivating, but troublesome if they appear not to align with students' personal values or self-efficacy. In line with identity-based motivation, these are particularly troublesome if students believe the misalignment to be unresolvable.

At this point we do not know why creativity was so troublesome for the mechanical engineering students, but across the cohort there was a notable and important difference between students' responses as they related to knowledge, teamwork or design, and those relating to creativity. Knowledge, teamwork and design were framed as competencies that could be developed during university study: for instance, learning to "utilise knowledge of chemistry and scientific processes in order to extract useful resources, and to communicate this knowledge" (chemical); or learning how to "design and build buildings and then work my way up to project management” (civil). In contrast, none of the students positioned creativity as a learned competency; rather, it was viewed as a personal characteristic and was often written of as a deficit. One student wrote simply that he was "maybe not the most creative person”. In line with Sfard and Prusak’s (2005) notion of congruent and incongruent identity states, there is an link here with Dweck's (1999) assertion that performance-based education is more likely to lead students to blame innate inability rather than focusing on self- 
improvement strategies. Indeed, creativity stood alone as being categorised as an innate ability rather than a developable attribute or skill. In this sense it was a demotivating feature.

The results suggest that a gap between self and the required characteristics of an engineer can be motivating if a student deems it possible to reduce the gap, but demotivating if a student identifies a characteristic over which there is perceived to be no control. This finding is deserving of further research to ascertain the extent to which students can be engaged in thinking and learning that is closer to the messy world of work, where they will be "performing work that is less focused on routine problem-solving and more focused on creative outcomes that involve new social relationships, novel challenges and the synthesising of ‘big picture’ scenarios” (McWilliam 2007, 5).

This brings to the fore the importance of providing students opportunities to explore both themselves and their intended profession. It illustrates the need for new approaches, including enhanced opportunities to engage with and in industry, to develop students' abilities to deal with the unknown not only in professional life but also within the personal and social domains (Baillie, Bowden and Meyer 2013).

The thesis that engineering students and graduates experience the concept of 'roles of engineers' as troublesome, transformative and potentially motivating is evidenced in numerous studies. Trevelan (2011), for example, asserts that engineering educators encourage misperceptions about engineering practice, especially by emphasising technical over sociotechnical activities. In line with this, Faulkner (2007) suggests that engineers can experience conflict between their identities as technical people and the reality of their roles being largely about people. Blandin (2012) and Case (2007) have found that identifying with engineering was motivating for students, and Lindsay et al. (2008) recommend curriculum design to inspire students to identify as student engineers rather than engineering students.

A logical response to this has been to expose students to engineering practice during their studies, and the benefits and challenges of these experiences are well documented. In Denmark, Du (2006, 39) took a novel perspective by focusing on the impact of project-based learning on students' identity development, and found unsurprisingly that students' professional identities are strengthened when working "in an actual practical engineering environment”. Mann, Price, Fons and Fae (2008), however, have questioned whether limited experience of the engineering professional gives students a false impression, warning that the risks of adopting a 'one-size-fits-all approach' must be acknowledged. Du’s (2006) focus on identity allays these fears with the observation that project-based learning helps students 
develop a professional engineering identity and self-awareness with which they confront some of the established cultural and hierarchical perceptions of engineering.

Engineering students have opportunities to be employed as interns or vacation students late in their engineering education. In Australia, the most common model is vacation employment before the final year of the engineering degree. In relatively rare 'sandwich' programs in Australia, students take internships after just three semesters of study. Our findings suggest that opportunities for professional experience early in engineering programs should be expanded, and that these need not be limited to experiences outside of the university (Davies and Rutherford 2012). It is feasible that students who are given space to explore possible futures without boundaries, even within the confines of the university, will consider roles beyond those presented to them or experienced by them. This includes consideration of the connections between engineering roles and broader individual interests.

The activities in our study are just one example of strategies that could be implemented and linked throughout an engineering program to help students explore possible selves. Other strategies include professional- and peer-mentor programs, opportunities to interview and hear from panels of engineers, guest lecturers from industry, and the use of portfolios. Kilgore, Sattler and Turns $(2012,17)$ have worked with students to develop portfolios through which students made valuable connections between experiences within and outside of the classroom and within and outside of engineering. As the authors note, in "engineering education, as in most majors, students' multiple selves are ignored in favour of the individual whose sole purpose is to logically progress toward some educated endpoint”. Their study is a prime example of engaging students in the construction of their salient identities by allowing them to bring multiple selves to the fore. Many of these opportunities exist within courses, but rarely are they linked together to form a cohesive focus on self and career development.

\section{Closing comments}

Combining the three frameworks of possible selves, threshold concepts, and identity-based motivation, was a new approach for us. Using all three frameworks enabled us to frame complementary research questions, to engage students in complementary learning activities, and to analyse the data through complementary lenses. Each approach contributed to improving our understanding of the problem and how it might be addressed, but perhaps the most exciting aspect of the study was that it showed us how a single well-planned workshop could reveal so much about students' engineering fears, expectations and aspirations, and about their individual interests. Simply engaging students in thinking about their possible 
selves prompted them to reorient their relationship with the learning that was discussed, strengthening Oyserman's assertion $(2010,1029)$ that "subtle shifts in contexts including shifts resulting from small interventions can have big effects on outcomes when they instantiate identity-behavior links”. This powerful and unexpected finding has remained with the students and with us, and has driven our resolve to further develop this work. Future research might further interrogate issues such as gendered experiences and expectations; perceptions and misperceptions about the characteristics of engineering work; the sources of students' perceptions about engineering; course and career choice; attrition; the role and impact of work-integrated learning; and pedagogical approaches to developing engineering identity.

\section{References}

Allie, Saalih, Mogamat N. Armien, Nicolette Burgoyne, Jennifer M. Case, Brandon I. CollierReed, Tracy S. Craig, Andrew Deacon et al. 2009. "Learning as acquiring a discursive identity through participation in a community: improving student learning in engineering education.” European Journal of Engineering Education 24 (4): 359-367. Australian National Engineering Taskforce. 2010. ANET Engineers Survey. Melbourne: Australian National Engineering Taskforce.

Baillie, Caroline, Bowden, John. A, \& Jan H. F. Meyer. 2013. “Threshold capabilities: threshold concepts and knowledge capability linked through variation theory.” Higher Education 65 (2): 227-246.

Bandura, Albert. 1997. Self-efficacy: The Exercise of Control. New York: Freeman.

Bennett, Dawn. 2012. The TILE Approach: Making the Link Between Future Selves and Learning. Sydney: Department of Industry, Innovation, Science, Research and Tertiary Education. Available at: http://www.olt.gov.au/altc-teaching-fellow-dawn-bennett

Biggs, John B. 1989. “Approaches to the enhancement of tertiary teaching.” Higher Education Research and Development 8: 7-25.

Biswas, Wahidul. 2012. The Importance of Industrial Ecology in Engineering Education for Sustainable Development. International Journal of Sustainability in Higher Education 13 (2): 119-132.

Cameron, Ian, Reidsema, Carl and Roger Hadgraft. 2011. “Australian Engineering Academe: A Snapshot of Demographics And Attitudes.” Paper presented at the 22nd Annual Conference of the Australasian Association for Engineering Education, 107-113, Fremantle, Western Australia. 
Blandin, B. 2012. "The Competence of an Engineer and How it is Built through an Apprenticeship Program: a Tentative Model." International Journal of Engineering Education 28 (1): 57-71.

Case, Jennifer. 2007. Rethinking Identity at the Core of Scientific and Technological Literacies: Insights from Engineering Education Research and Practice in South Africa. In Promoting Scientific Literacy: Science Education Research in Transaction Symposium, edited by Cedric Linder and Per-Olof Wickman 95-99. Uppsala, Sweden: Academia online network.

Coffey, Jane. 2012. Youth Career Choices: a Comparison of Industry and Ballet. Phd Diss., Curtin Univ. http://espace.library.curtin.edu.au:80/R?func=dbin-jumpfull\&local_base=gen01-era02\&object_id=188765. Accessed May 12, 2013.

Creswell, John W. 2007. Qualitative Inquiry \& Research Design: Choosing Among Five Approaches. $2^{\text {nd }}$ ed. Thousand Oaks, CA: Sage.

Czikszentmihalyi, Mihaly. 2007. Developing Creativity. In Developing creativity in higher education, edited by Norman Jackson, Martin Oliver, Malcolm Shaw \& James Wisdom, xviii - xx. New York: Routledge.

Davies, J. W., \& Rutherford, U. 2012. "Learning from Fellow Engineering Students who have Current Professional Experience.” European Journal of Engineering Education, 37 (4): 354-365.

Du, Xiang-Yun. 2006. “Gendered Practices of Constructing an Engineering Identity in a Problem-Based Learning Environment.” European Journal of Engineering Education 31 (1): 35-42.

Dweck, Carol. 1999. Self-Theories: Their Role in Motivation, Personality and Development. Philadelphia, PA: Psychology Press.

Engineers Australia. 2011. Stage 1 Competency Standard for the Professional Engineer. Barton, ACT: Institution of Engineering Australia.

Engineering Council. 2010. The Accreditation of Higher Education Programmes: UK Standard for Professional Engineering Competence. London: Engineering Council http://www.engc.org.uk/ecukdocuments/internet/document\%20library/AHEP\%20Broch ure.pdf. Accessed May 12, 2013.

Faulkner, Wendy. 2007. “'Nuts and Bolts and People’: Gender-troubled Engineering Identities.” Social Studies of Science 37 (3): 331-356. 
Fischer, Martin, Nick Boreham and Barry Nyhan (eds). 2004. European Perspectives on Learning at Work: the Acquisition of Work Process Knowledge. Luxembourg: Office for Official Publications for the European Communities.

Fox, Mary F. 2008. “Institutional Transformation and the Advancement of Women Faculty: the Case of Academic Science and Engineering.” Higher Education: Handbook of Theory and Research, 23 (2008): 73-103.

Godfrey, Elizabeth, Tim Aubrey and Robin King. 2010. "Who Leaves and Who Stays? Retention and Attrition in Engineering Education.” Engineering Education 5 (2), n.

p. http://78.158.56.101/archive/engineering/journal/index.php/ee/article/view/232/227.h

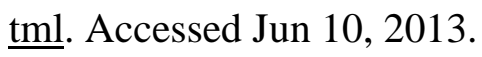

Godfrey, Elizabeth and Robin King. 2011. Curriculum Specification and Support for Engineering Education: Understanding Attrition, Academic Support, Revised Competencies, Pathways and Access. Sydney: Australian Learning and Teaching Council.

Harlow, Ann, Jonathan Scott, Mira Peter and Bronwen Cowie. 2011. “'Getting stuck’ in analogue electronics: threshold concepts as an explanatory model.” European Journal of Engineering Education 36 (5): 435-447.

Harrison, Matthew. 2012. Jobs and Growth: the Importance of Engineering Skills to the UK Economy. London: Royal Academy of Engineering.

Johnson, Peter N. 1996. Changing the Culture: Engineering Education into the Future. Barton, ACT: The Institution of Engineers, Australia.

Kabo, Jens D., and Caroline C. Baillie. 2009. Seeing Through the Lens of Social Justice: A Threshold for Engineering. European Journal of Engineering Education 34 (4): 317 325.

Kaspura, Andre. 2012. The Engineering Profession: a Statistical Overview. 9th Ed. Barton, ACT: Institution Of Engineers, Australia.

Kilgore, Deborah, Brook Sattler and Jennifer Turns. 2012. "From Fragmentation to Continuity: Engineering Students Making Sense of Experience through the Development of a Professional Portfolio.” Studies in Higher Education Published as an iFirst article. http://dx.doi.org/10.1080.03075079.2011.610501. Accessed May 12, 2013.

Leydens, Jon A. 2012. Sociotechnical Communication in Engineering: an Exploration and Unveiling of Common Myths. Engineering Studies 4 (1): 1-9. http://dx.doi.org/10.1080/19378629.2012.662851. Accessed October 11, 2012. 
Lindsay, Euan, Roger Munt, Helen Rogers, David Scott and Karen Sullivan. 2008.

Engineering Students or Student Engineers? In Annual Conference of the Australasian Association for Engineering Education. Yeppoon: Australasian Association for Engineering Education.

Male, Sally. A, Mark B. Bush and Elaine S. Chapman. 2011. “An Australian Study of Generic Competencies Required by Engineers.” European Journal of Engineering Education 36 (2): 151-163

Male, Sally A. 2012. Engineering Thresholds: an Approach to Curriculum Renewal. Sydney: Australian Government Office for Learning and Teaching.

Male, Sally and Caroline A. Baillie. 2011. Engineering Threshold Concepts. In SEFI Annual Conference. Lisbon: European Society for Engineering Education.

Mann, Llewelyn, Prue Howard, Fons Nouwens and Fae. 2008. Professional Identity: a Framework for Research in Engineering Education. Proceedings 2008 AaeE Conference, 7-10 December 2008, Yeppoon. http://aaee.com.au/conferences/papers/2008/aaee08_submission_T1A2.pdf. Accessed February 1, 2013.

Marcia, John. 1966. “Development and Validation of Ego-identity Status.” Journal of Personality and Social Psychology 3 (1): 551-558.

Marcus, Hazel and Paula Nurius. 1986. Possible Selves. American Psychologist 41 (9): 954969.

Mcwillian, Erica. 2007. Is Creativity Teachable? Conceptualising the Creativity/Pedagogy Relationship in Higher Education. Proceedings $30^{\text {th }}$ HERDSA Annual Conference: Enhancing Higher Education, Theory and Scholarship, 8-11 July 2007, Adelaide. http://www.herdsa.org.au/?page_id=217. Accessed July 1, 2013.

Meyer, Jan H. F and Ray Land. 2003. Enhancing Teaching-Learning Environments in Undergraduate Courses. Occasional Report 4. Edinburgh: Economic and Social Research Council. http://www.etl.tla.ed.ac.uk/docs/ETLreport4.pdf. Accessed February 1, 2013.

Mills, Julie E., Mary Ayre, M and Judith Gill. 2010. Guidelines for the Design of Inclusive Engineering Education Programs. Sydney: Australian Learning and Teaching Council. Minsky, Marvin. 1975. A Framework for Representing Knowledge. In The Psychology of Computer Vision, edited by Patrick H. Winston 211-277. New York: McGraw-Hill. Moustakas, Clark. 1994. Phenomenological Research Methods. Thousand Oaks, CA: Sage. 
Oyserman, Daphna. 2007. Social Identity and Self-Regulation. In Social Psychology:

Handbook of Basic Principles, edited by Arie Kruglanski and Edward T. Higgins, $2^{\text {nd }}$ ed. New York: Guilford Press.

Oyserman, Daphna and Mesmin Destin. 2010. “Identity-Based Motivation: Implications for Intervention.” The Counseling Psychologist 38 (7): 1001-1043.

Parkinson, David. 2011. Investigation of Experiences of Threshold Concepts by Engineering Students. Final year project diss. (unpublished), Univ. of Western Australia.

Prados, John W. 1998. Engineering Education in the United States: Past, Present and Future. Paper presented at the International Conference on Engineering Education, August 17-20, Brazil, Rio de Janeiro. http://www.ineer.org/Events/ICEE1998/Icee/Index.htm. Accessed May 10, 2013.

Quinlan, Kathleen, Sally Male, Caroline Baillie, Artemis Stamboulis, Johnny Fill and Zahira Jaffer.2013). "Methodological Challenges in Researching Threshold Concepts: a Comparative Analysis of Three Projects.” Higher Education 66 (5): 585-601.

Schnare, Ben, Peter MacIntyre and Jesslyn Doucette. 2012. Possible Selves as a Source of Motivation for Musicians. Psychology of Music 40 (1): 94-111.

The Senate. 2012. The Shortage of Engineering and Related Employment Skills (Education Employment and Workplace Relations Committee, trans.). Canberra, ACT: Commonwealth of Australia.

Sfard, Anna and Anna Prusak. 2005. "Telling identities: In search of an analytic tool for investigating learning as a culturally shaped activity.” Educational Researcher 34 (4): $14-22$.

Stryker, Sheldon and Peter J. Burke. 2000. “The Past, Present, and Future of an Identity Theory.” Social Psychology Quarterly 63 (4): 284-297.

Sullivan, William, Sheri D. Sheppard and Kelly Macatangay, K. 2009. Educating Engineers: Designing for the Future. Field Book Highlights and Summary. Stanford, CA: Carnegie Foundation for the Advancement of Teaching. http://www.carnegiefoundation.org/elibrary/book-highlights-educating-engineersdesigning-future-field. Accessed May 10, 2013.

Tilli, Sabbia and James Trevelyan. 2010. “Labour Force Outcomes for Engineering Graduates in Australia.” Australasian Journal of Engineering Education 16 (2): 101-122.

Trevelyan, James P. 2011. Are we Accidentally Misleading Students about Engineering Practice? Paper presented at the Research in Engineering Education Symposium, October 4-7, Spain, Madrid. 
Trevelyan, James P. and Sabbia Tilli. 2007. Published Research on Engineering Work.

Journal of Professional Issues in Engineering Education and Practice 133 (4): 300-307.

Yates, Athol. 2012. Engineering WA 2020: A State Capability and Engineering Workforce

Strategy. West Perth: Engineers Australia, Western Australian Division. 


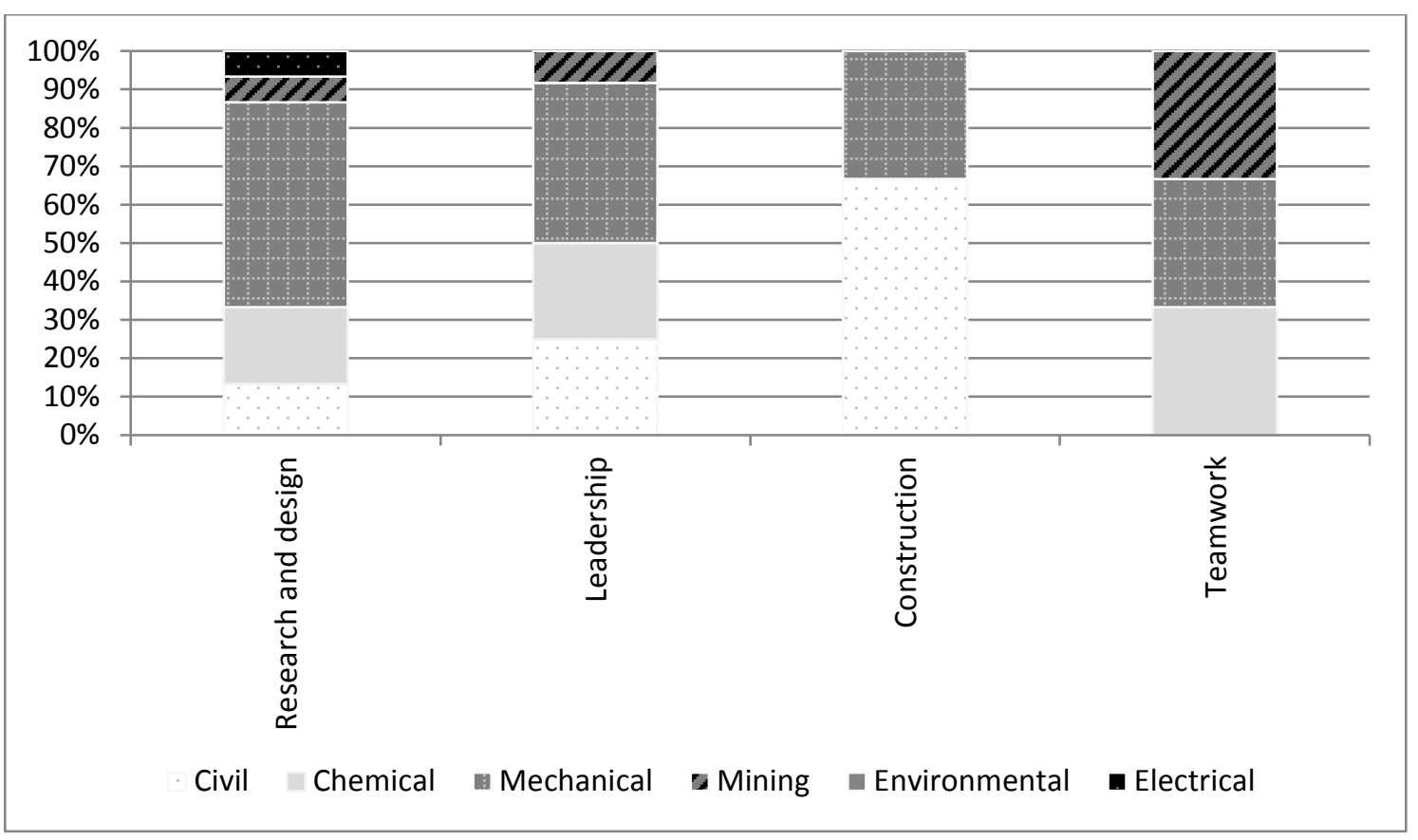

Figure 1: Student response: Personal role as an engineer (\% of coded responses) 